\title{
Experimental Examination of Fluid Flow in Fractured Carbon Storage Sealing Formations
}

\author{
Dustin Crandall $^{1,2}$, Grant Bromhal ${ }^{1}$ \\ ${ }^{1}$ National Energy Technology Laboratory, Morgantown, USA \\ ${ }^{2}$ URS, Morgantown, USA \\ Email: Dustin.Crandall@contr.netl.doe.gov
}

Received June 28, 2013; revised July 31, 2013; accepted September 2, 2013

Copyright (C) 2013 Dustin Crandall, Grant Bromhal. This is an open access article distributed under the Creative Commons Attribution License, which permits unrestricted use, distribution, and reproduction in any medium, provided the original work is properly cited.

\begin{abstract}
This report describes a series of experiments where $\mathrm{CO}_{2}$-saturated-brine flow through fractured seal rocks from three sites within the continental United States that are being considered, or are actively being used, for CCUS pilot studies were examined. The experiments were performed over multiple weeks by injecting $\mathrm{CO}_{2}$ saturated brine through fractured samples, and were scanned with a computed tomography scanner at regular intervals over the course of the experiment while kept at representative reservoir pressures. The goal was to evaluate the change in the fracture flow that would result from a $\mathrm{CO}_{2}$ leakage event so that accurate relationships can be implemented in numerical models to assess risk. Of the three different formations studied in this series of fractured seal formation $\mathrm{CO}_{2}$-saturated-brine flow through experiments, only one formation had a reaction that was greater than the noise in the system. Reactions within the Tuscaloosa claystone sample appeared to reduce the transmissivity of the fracture slightly over the 39 day experiment. The change in the geometry of the fracture was not great enough to view with the medical CT images that were captured during the experiment. All other tests showed a minimal amount of change in the fracture and fracture flow properties.
\end{abstract}

Keywords: CCUS; Fractured Seal; CT Scanning; Fractured Rock Flow

\section{Introduction}

Since the industrial revolution, the amount of carbon dioxide $\left(\mathrm{CO}_{2}\right)$ in the atmosphere has risen at an unprecedented rate, resulting in global warming and climate change [1]. In an attempt to reduce the anthropogenic $\mathrm{CO}_{2}$ released to the atmosphere, geologic $\mathrm{CO}_{2}$ sequestration is being actively examined. Carbon capture, utilization, and storage (CCUS) involves pumping $\mathrm{CO}_{2}$ far below the surface of the earth into high permeability $(k)$ and high porosity $(\phi)$ reservoirs, which have a low $k$ and low $\phi$ seal formation above the reservoir to stop the vertical migration of the $\mathrm{CO}_{2}$ back to the surface [2,3]. Numerical simulations, cost benefit analysis, and field tests are all underway to determine the feasibility of CCUS as a greenhouse gas mitigation activity. For CCUS to have a meaningful effect on the percent of $\mathrm{CO}_{2}$ in the atmosphere, the $\mathrm{CO}_{2}$ must remain in the subsurface for 100 s to 1000 s of years [1]. One concern of the long term viability of storage locations is the presence of fractures in the low $k / \phi$ seal rock above the $\mathrm{CO}_{2}$ reservoirs and the potential for these fractures to allow $\mathrm{CO}_{2}$ leakage to the surface.
A typical vertical fracture geometry is shown in Figure 1 where the aperture, $b$, is much less than the fracture width, $W$, height, $H$, and length, $L$. Flow through rock fractures has been a research topic of interest for decades [4,5]. Analytical models were developed for laminar, single phase fluid flow in a narrow fracture, bounded by impermeable walls, by simplifying the Navier-Stokes equations of fluid continuity

$$
Q=-\frac{W b^{3}}{12 \mu} \frac{\Delta P}{L}
$$

where $Q$ is the mass flow rate, $\mu$, is the dynamic viscosity of the fluid in the fracture, and $P$ is the pressure along the fracture. Equation (1) is commonly referred to as the "cubic law" of flow in fractures.

Experimentally the cubic law has been shown to be accurate when $b \ll W, b \ll L$, fracture wall roughness is small, the flow is laminar, and the fluid acts in a Newtonian fashion. There is a similarity of the cubic law to Darcy's law for flow through porous media [6],

$$
Q=k \frac{A}{\mu} \frac{\Delta P}{L}
$$




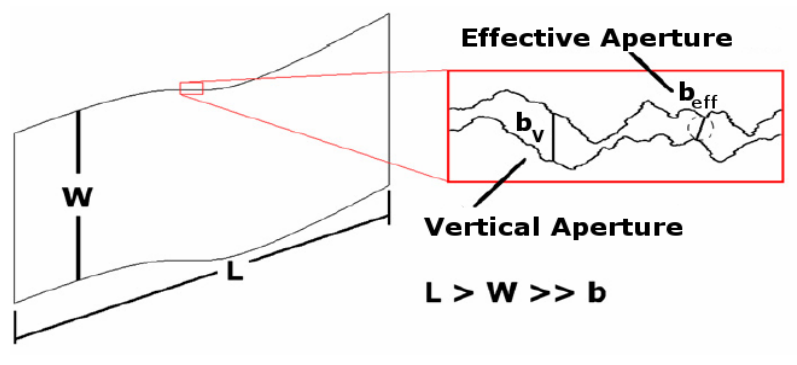

Figure 1. Typical fracture geometry.

where $k$ is the permeability of the porous medium and $A$ is the cross-sectional area of the porous medium perpendicular to flow. Assuming that the $A$ of a fracture is equal to $W^{*} b$, the definition of a fracture permeability, $k_{\text {fracture, }}$ as [7]

$$
k_{\text {fracture }}=\frac{b^{2}}{12}
$$

seems reasonable. Often it is more convenient to measure a combined transmissivity $(T)$, where $T$

$$
T=k_{\text {fracture }} A
$$

where $A$ is the mean of the fracture area perpendicular to the flow direction. Because the $b$ of a fracture varies, the measurement of a combined $T$ avoids having to calculate an average $b$ for the $A$ calculation, and permits an equivalent hydraulic aperture, $b_{H}$, to be calculated for use in discrete fracture flow models

$$
b_{H}^{3}=\frac{12 T}{W}
$$

As shown in Figure 1, the mechanical $b$ can be defined in several ways, as the vertical difference between two surfaces, $b_{v}$, or as the largest distance that can be inscribed within the fracture walls, an effective (or perpendicular) aperture, $b_{\text {eff. }}$ In the remainder of this report $b$ is used to designate a physical measurement of the spacing between fracture walls and $b_{H}$ is used to designate the flow relationship shown in Equation (8). Previous studies [8-10] have shown that for a rough walled fracture $b_{H}<$ $b_{v}$ and $b_{H}<b_{\text {eff, }}$, but the difference between the $b_{v}$ and $b_{\text {eff }}$ is not as great as the difference with the $b_{H}$.

Numerous studies have shown that applying an external force to a fractured core can reduce the $b$ and $b_{H}$ $[11,12]$. This has been shown to be due primarily to the increase in zero-aperture locations, or contact zones, within the fractures [13,14]. An increase in the contact locations increases the tortuosity of fluids moving through the fracture, which increases the length individual fluid particles, must travel to traverse the macroscopic fracture length. Increasing the contact between fracture walls also creates more restrictive flow paths through the fracture. Both of these effects reduce the $T$ of the fracture.

In a similar fashion, changes due to chemical interac- tions between the fluid in a fracture and the fracture surface can have an effect on the $b$ and $b_{H}$. Numerical studies of reactive rocks and low $\mathrm{pH}$ fluid flow have shown significant increases in $T$. Experimental studies have shown that low $\mathrm{pH}$ solutions can dissolve carbonates from rock fracture walls and increase $T$ [15-17]. Conversely, experiments have shown that dissolution of fracture surfaces can decrease the $b$ and $b_{H}$ [18]. The complex interactions between these geochemical reactions and the $T$ of a fracture are of importance when considering $\mathrm{CO}_{2}$ leakage from CCUS reservoirs. Site specific fracture and fluid reactions can have different effects on the geometry and flow properties of fractures.

When $\mathrm{CO}_{2}$ is injected into a CCUS reservoir, it will mix with the in-place or native fluid, often brine. The resultant plume of $\mathrm{CO}_{2}$-saturated brine will have a lower $\mathrm{pH}$ than the non-saturated brine and has the potential to react with rocks within the seal, reservoir, and in the well-bore. Huerta et al. [19] have shown a complex relationship with sealing occurring in long fractures of wellbore cement when a low-pH fluid migrates through the void. Deng et al. [20] and Ellis et al. [21] have shown that when the rock fracture has a varied composition, the more reactive zones of minerals on the fracture walls will tend to dissolve in low $\mathrm{pH}$ environments and increase the $b$, but this has been shown to minimally effect the $b_{H}$. A complex interaction between the site specific fractured rock mass and the fluids migrating through the fracture can result in different interactions that will affect the potential rate of flux through fractures.

The current study is an examination of $\mathrm{CO}_{2}$-saturatedbrine flow through fractured seal rocks from three sites within the continental United States that are being considered or are actively being used for CCUS pilot studies. The experiments were performed over multiple weeks by injecting $\mathrm{CO}_{2}$ saturated brine through fractured samples, and were scanned with a Computed Tomography (CT) scanner at regular intervals over the course of the experiment while kept at representative reservoir pressures. The goal was to evaluate the change in $T$ that would result from a $\mathrm{CO}_{2}$ leakage event so that accurate relationships can be implemented in numerical risk assessment models.

\section{Seal Formations}

Three cores from sealing formations at active or proposed $\mathrm{CO}_{2}$ injection sites in the continental United States were acquired, fractured, and used for multiple week long $\mathrm{CO}_{2}$-saturated-brine flow through experiments. A short description of the formation rock studied, and how the location of these cores is related to $\mathrm{CO}_{2}$ injection follows.

\subsection{Kirtland Shale—San Juan Basin}

The Kirtland Shale used for this study was acquired as a 
preserved core from injection well EPNG com A at the Pump Canyon Site in the north central portion of the San Juan Basin, New Mexico [22]. In October 2000 a multiple year project with the United States Department of Energy (USDOE) and industry partners was launched to evaluate the feasibility of $\mathrm{CO}_{2}$ sequestration in unminable coal seams using enhanced coal bed methane recovery technology [23]. Since 2000 there have been several $\mathrm{CO}_{2}$ sequestration injection pilot projects within the San Juan Basin, primarily focused on injection into the Fruitland Coal formation [24]. Studies of fault locations, tracer movement, and understanding the complex geology of the sealing formations above the Fruitland Coal [25] indicate that detailed studies of how these seals will react to $\mathrm{CO}_{2}$-staurated-brine flow could be of importance when evaluating the long term risk associated with storage here.

The sample used in this study was from a depth of $2049 \mathrm{ft}(624.5 \mathrm{~m})$ which is in the Upper Kirtland Shale formation [22]. These samples were preserved by TerraTek by retrieving the core from the aluminum core sleeve with drilling mud, then wrapping layers of plastic, aluminum foil, and dipping in a core seal wax.

The temperature and pressure conditions used for the Kirtland Shale flow through tests at were calculated based on the USDOE report by Heath et al. [22] and heat flow records of the Fruitland coals [26]. A pore pressure of $1620 \mathrm{psi}(11.17 \mathrm{MPa})$ and a core temperature of $27^{\circ} \mathrm{C}$ $\left(80.6^{\circ} \mathrm{F}\right)$ were calculated from the depth and reported pressure/temperature geologic gradient. A simple brine recipe based upon USGS measurements of in-situ brines at the depth from which this sample was obtained in the San Juan Basin and is shown in Table 1.

Coring of these samples was not straightforward due to the highly friable nature of the Kirtland Shale. After attempts to sub-core the preserved sample using traditional core drills was shown to be non-effective, a 1.5 in $(3.81 \mathrm{~cm})$ diameter sub-core was obtained with an OMAX Jet Machining Center, OMAX 2626 (OMAX Corp., Kent, WA). After the sample was sub-cored a thin layer of 5 Minute Epoxy (Devcon, Danvers, MA) was spread on the exposed surface, to protect against atmospheric degradation. This epoxy layer was allowed to cure the subcore was turned on a lathe to produce uniform and smooth sub-cores for the flow through study. The final prepared sub-core of the Upper Kirtland Shale is shown in Figure 2. The friable nature of the Kirtland Shale and the unique sub-coring process resulted in a competent fractured core.

\subsection{Eau Claire Mudstone-Illinois Basin}

The Eau Claire mudstone sample used for this study was acquired as part of the ongoing FutureGen 2.0 characterization from well FGA\#1 in Morgan County Illinois
Table 1. Brine recipes.

\begin{tabular}{ccccccc}
\hline & \multicolumn{2}{c}{ Kirtland Shale } & \multicolumn{2}{c}{$\begin{array}{c}\text { Eau Claire } \\
\text { Mudstone }\end{array}$} & \multicolumn{2}{c}{$\begin{array}{c}\text { Tuscaloosa } \\
\text { Siltstone }\end{array}$} \\
\hline \multirow{2}{*}{ Chemical } & $\begin{array}{c}\text { Mole/kg } \\
\text { water }\end{array}$ & $\begin{array}{c}\mathrm{g} / \mathrm{L} \\
\text { water }\end{array}$ & $\begin{array}{c}\text { Mole/kg } \\
\text { water }\end{array}$ & $\begin{array}{c}\mathrm{g} / \mathrm{L} \\
\text { water }\end{array}$ & $\begin{array}{c}\text { Mole/kg } \\
\text { water }\end{array}$ & $\begin{array}{c}\mathrm{g} / \mathrm{L} \\
\text { water }\end{array}$ \\
\hline $\mathrm{NaCl}$ & 58.443 & 17.00 & 1.594 & 93.174 & 1.88 & 109.63 \\
$\mathrm{KCl}$ & 74.552 & 0.295 & 0.0311 & 2.317 & 0.008 & 0.60 \\
$\mathrm{CaCl}_{2}$ & - & - & 0.3547 & 39.366 & 0.292 & 32.40 \\
$\mathrm{MgCl}_{2}$ & 95.212 & 0.075 & 0.0892 & 8.495 & 0.0434 & 4.13 \\
$\mathrm{MgSO}_{4}$ & - & - & 0.0141 & 1.695 & - & - \\
$\mathrm{NaHCO}_{3}$ & - & - & 0.00172 & 0.145 & - & - \\
$\mathrm{NaBr}$ & - & - & - & - & 0.0052 & 0.53 \\
$\mathrm{Cl}_{2} \mathrm{Sr}$ & - & - & - & - & 0.0079 & 1.248 \\
\hline
\end{tabular}

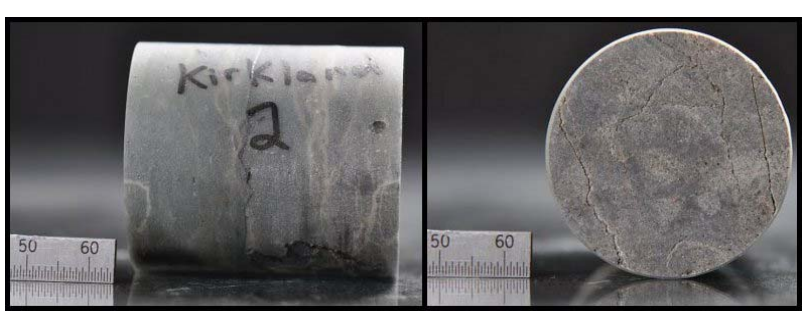

Figure 2. Prepared sub-core of upper Kirtland shale.

[27]. The Eau Claire overlies the Mount Simon Sandstone, a large formation with an estimated $\mathrm{CO}_{2}$ storage potential between 16,900 and 67,600 million metric tons of $\mathrm{CO}_{2}$ [2]. The Mount Simon Sandstone has a high $\phi$, high $k$, large areal extent, is thick, and is located in a region with many high volume point source $\mathrm{CO}_{2}$ emitters $[2,27,28]$.

The portion of the Eau Claire caprock studied here is from a depth of 3854 feet $(1174.7 \mathrm{~m})$ and was saved for analysis at NETL during a detailed well characterization performed at PNNL [27] with the assistance of Core Laboratories (Houston, TX). This sample is from the bottom of the Lombard member, a primary seal for the Mount Simon Sandstone.

The in-situ pressure was calculated to be approximately 1850 psi based on published literature and the depth of the retrieved core. A confining pressure of 1850 psi was maintained during the Eau Claire fracture flow experiments with fluid pressures that varied between 1600 and 1700 psi (constant fluid injection rate). The brine recipe was determined with Deng et al. [20], based on the work of [29], and is listed in Table 1.

The six inch long sample of the Eau Claire caprock was sub-cored using standard core drills to make 1 in $(2.54 \mathrm{~cm})$ diameter samples. Because the sub-cores remained intact each sub-core needed to have a fracture mechanically induced to provide a flow path. This was done perpendicular to the bedding planes using a modified Brazilian technique at NETL. Two samples were selected to perform the experimental flow through tests, 
as shown in Figure 3.

\subsection{Tuscaloosa Claystone-Gulf Coast}

The Lower Tuscaloosa claystone used for this study was acquired from the Mississippi Test site of the Southeast Regional Carbon Sequestration Partnership (SECARB) [30]. The sample was preserved from a depth of 8569.75 ft $(2612 \mathrm{~m})$ from well HH-38927 at the Jackson County Mississippi Power's Plant Daniel near Escatawpa Mississippi. The purpose of this SECARB test was to identify and validate the $\mathrm{CO}_{2}$ storage potential of deep saline reservoirs in the Gulf Coast region. Approximately 3020 tons of $\mathrm{CO}_{2}$ were successfully injected at the Plant Daniel site in 2008 [31].

Due to time constraints in the lab at the start of this experiment we were unable to photograph the core prior to the flow through test. A similar sample $(3-50)$ from the same well is shown in Figure 4. The depth of the core and a standard geological pressure gradient was used to determine an appropriate confining pressure of 4000 psi. The as-received sample was fractured separate prior to our use of the core in the laboratory. The sample appeared to have desiccated slightly and broke along several bedding planes. The 1.5 in $(3.81 \mathrm{~cm})$ diameter and 2.5 in $(6.35 \mathrm{~cm})$ long sample was coated with epoxy to ensure it remained intact over the experiment, but no additional mechanical fracturing was needed. A brine recipe based on supplemental data on brine composition presented by Lu et al. [32] that was used for the experiment is shown in Table $\mathbf{1 .}$

\section{Methods}

NETL's Universal Systems HD350-E $4^{\text {th }}$ generation refurbished medical CT scanner with 4800 detectors and one rotating X-Ray source was used to non-destructively image the internal structure of the fractured cores. This scanner has capability to operate at $140 \mathrm{kV}$ and $400 \mathrm{~mA}$, has a maximum resolution in the $\mathrm{x}-\mathrm{y}$ plane (perpendicular to the core length) of $0.25 \mathrm{~mm}\left(9.84\left(10^{-3}\right)\right.$ in) and 1 $\mathrm{mm}\left(3.94\left(10^{-2}\right)\right.$ in) along the axial direction. NETL's medical scanner is shown in Figure 5 with four Isco pumps (Teledyne Isco, Lincoln Nebraska) in foreground and a Hassler style core holder (Core Laboratories, Tulsa Oklahoma) that was used to contain the fractured core, while applying both axial and radial pressure to the core during flow tests.

Dual-energy scanning was used to improve the computed tomography number (CTN) to density conversions that were used in these experiments. Dual-energy scanning is the processes of scanning at two energy levels to maximize the Compton scattering effects at high energy and maximize the photoelectric adsorption effect at low scanning energies [33]. This has been used for several

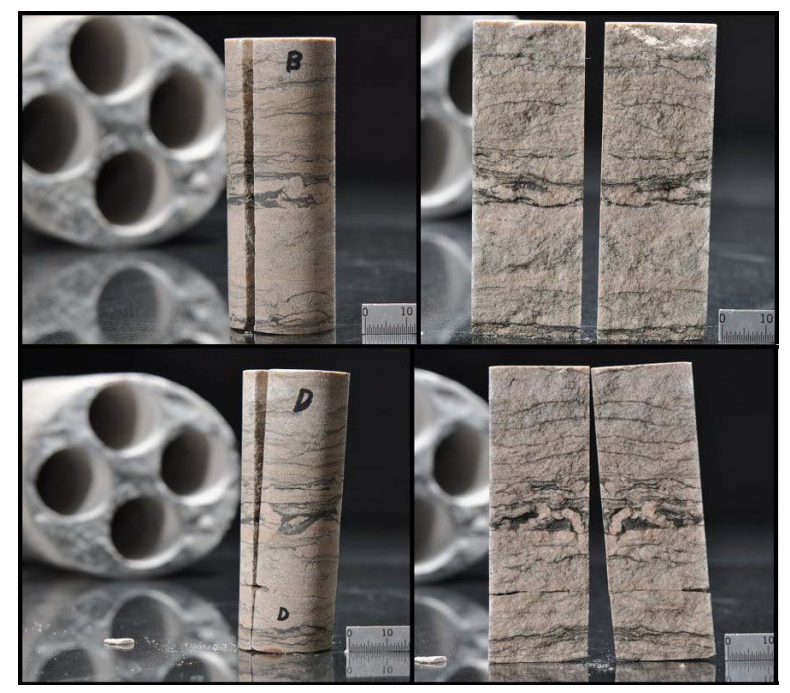

Figure 3. Eau Claire fractured sub-cores B and D.

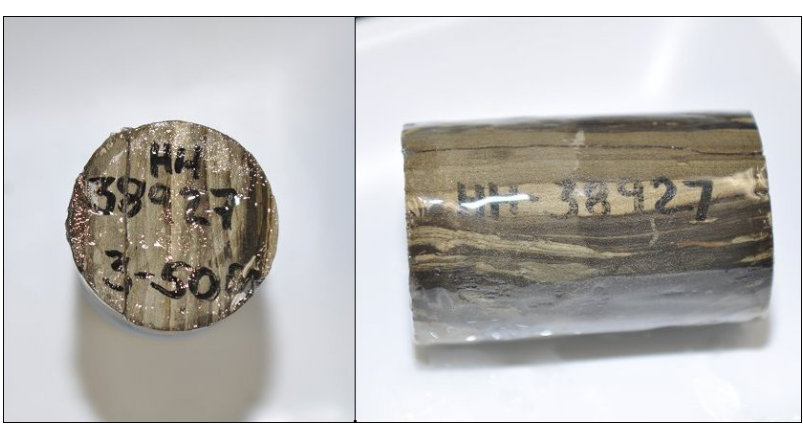

Figure 4. Fractured Tuscaloosa core.

other studies at NETL where small changes within a geologic sample are being examined [34,35]. In order to calibrate the relationship between the CTN and density several different materials with known density were scanned with the same CT scanning parameters as the fractured samples. These calibration samples included acrylic, nylon, Teflon, and other materials that are of similar density to geologic samples.

A Hassler style pressure vessel was used to constrain the fractured core during the flow through tests. As is shown in Figure 5 the cylindrical core holder is placed in the center of the CT scanner orifice and moved through the X-Ray field. This scanning was performed twice daily during standard working days (Monday through Friday) and once on the weekend days (Saturday and Sunday). The design of the core holder enables a confining pressure to be applied to the fractured sub-core while fluids are injected into the sample. A simplified diagram in Figure 6 shows how this system works. An Isco pump was used to increase the pressure in the annulus between the rubber sleeve containing the fractured core and the outside of the core holder with nitrogen. Another Isco pump was used to inject a mixture of $\mathrm{CO}_{2}$ and brine (labeled $\mathrm{H}_{2} \mathrm{O}$ in Figure 6). A pressurized mixing vessel 


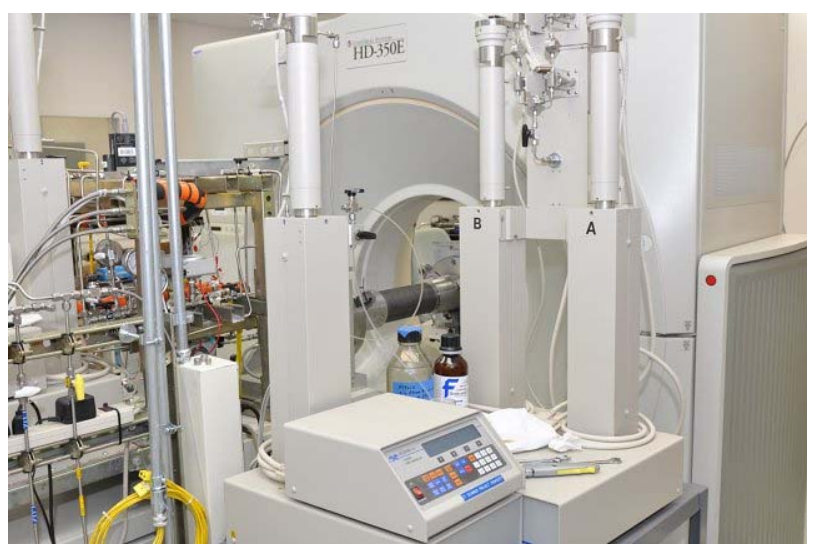

Figure 5. Medical CT scanner with Hassler style core holder and ancillary flow apparatus.

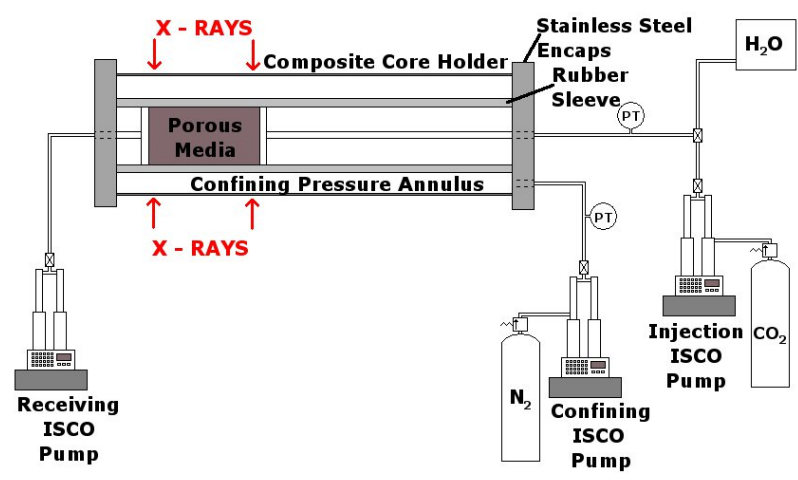

Figure 6. Schematic of flow through system with pumps and core holder.

was used to keep the brine saturated with $\mathrm{CO}_{2}$ prior to being injected into the core holder. At the outlet of the core holder another Isco pump was used in receiving mode to capture the fluids after they moved through the core. By using Isco pumps on both sides of the system a constant injection rate could be set, with settings to ensure that the pressure inside of the core and rubber sleeve did not increase above the confining pressure.

The injection flow rates and temperature of the system varied for each experiment. For the first test, the Kirtland shale flow, elevated temperature $\left(80.6^{\circ} \mathrm{F}\right)$ and constant pressure at the injection side of the core was tested. The temperature controllers were unwieldy and not used for the following tests. The constant injection pressure resulted in unstable flow patterns and collection of effluent from the exit side of the system was not possible at times. For the following tests a constant injection rate was set with the Isco pumps with additional software controls to ensure the pore pressure did not exceed the confining pressure. In this fashion, as long as the injection pressure was less than the confining pressure the flow rate was constant. When the injection pressure increased to a value close to the pore pressure the flow rate was decreased to ensure safe operations.
A combination of LabView (National Instruments, Austin TX), manual recording, and direct recordings from the Icso pumps was used to capture the pressure and flow rate information during the experiments. Initial LabView virtual instruments did a poor job of recording the data, frequently crashing with the out-dated system that was installed in the laboratory. Flow results from the final tests are of higher quality due to solutions being found to these data collection issues.

\section{Results}

Individual results from the four experiments performed on the three different fractured seal formations are described in this section. The dates of the tests performed, the pressure conditions, and the injection rates are shown in Table 2. Slices of a medical CT scan of the fractured Kirtland Shale sample are shown in Figure 7. These "slices", and all other medical CT scanner slices in this document, were obtained from the raw 16-bit data files that were generated by the medical CT scanner reconstruction software. The reconstruction algorithm that converted the X-Ray attenuation data to the $3 \mathrm{D}$ grayscale images occurred inside the HD-350E software prior to researcher manipulation. Several features can be noted from Figure 7.

1) The core is heterogeneous, with both high density zones (lighter regions) and fracture zones (darker regions) throughout the core.

2) The fractures are small compared to the $0.25 \mathrm{~mm} \times$ $0.25 \mathrm{~mm} \times 1.0 \mathrm{~mm}$ voxel resolution of the medical CT images.

3) The fracturing along the core is non-uniform. There is no discernible primary fluid pathway through the middle of the core as one would typically find in a standard mechanically fractured core. The geologic structure of the core and unique coring technique both contributed to this fracturing pattern.

With the above features noted, small changes in the structure of the fractures during the flow experiment would not be expected to be readily apparent from a thresholding procedure to isolate the fracture of the medical CT data.

As mentioned previously a constant pressure at the injection side of the core was held during this experiment. The LabView module intended to capture the pressure and flow information failed after several days. Written measurements of the volume of effluent in the downstream Isco pump were recorded over the remainder of the experiment. As is shown Figure 8 the bulk flow through the core remained fairly constant over the test duration. The flow rate of approximately $1 \mathrm{ml} /$ day was maintained with a constant differential pressure across the core of -25 psi. No noticeable change in the relationship between differential pressure across the fractured 
Table 2. Experimental parameters of flow-through tests.

\begin{tabular}{ccccccc}
\hline & Start Date & End Date & $\begin{array}{c}\text { Number of } \\
\text { Days }\end{array}$ & $\begin{array}{c}\text { Confining } \\
\text { Pressure }(\mathrm{psi})\end{array}$ & $\begin{array}{c}\text { Maximum Pore } \\
\text { Pressure }(\mathrm{psi})\end{array}$ & $\begin{array}{c}\text { Injection Rate } \\
(\mathrm{ml} / \mathrm{min})\end{array}$ \\
\hline Kirtland Shale & $1 / 12 / 2012$ & $2 / 6 / 2012$ & 25 & 1850 & 1620 & $\approx 6.9\left(10^{-4}\right)^{*}$ \\
Eau Claire \#1 & $9 / 4 / 2012$ & $9 / 26 / 2012$ & 22 & 1850 & 1650 & 0.013 \\
Eau Claire \#2 & $10 / 7 / 2012$ & $10 / 26 / 2012$ & 19 & 1850 & 1650 & $0.013 / 0.026$ \\
Tuscaloosa & $12 / 21 / 2012$ & $1 / 29 / 2013$ & 39 & 4000 & 3750 & 0.013 \\
\hline
\end{tabular}

${ }^{*}$ Constant pressure injection, flow rate varied.

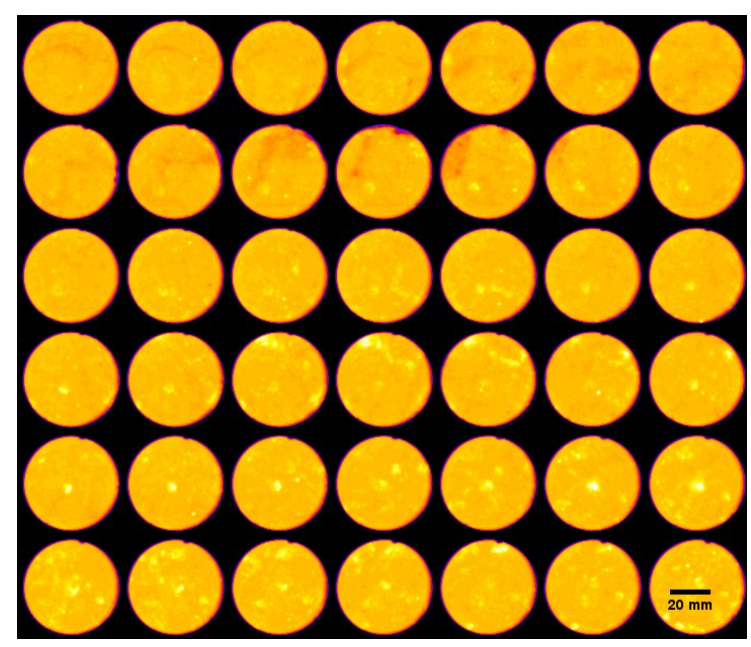

Figure 7. False color medical CT slices of fractured Kirtland shale sample, XY planes.

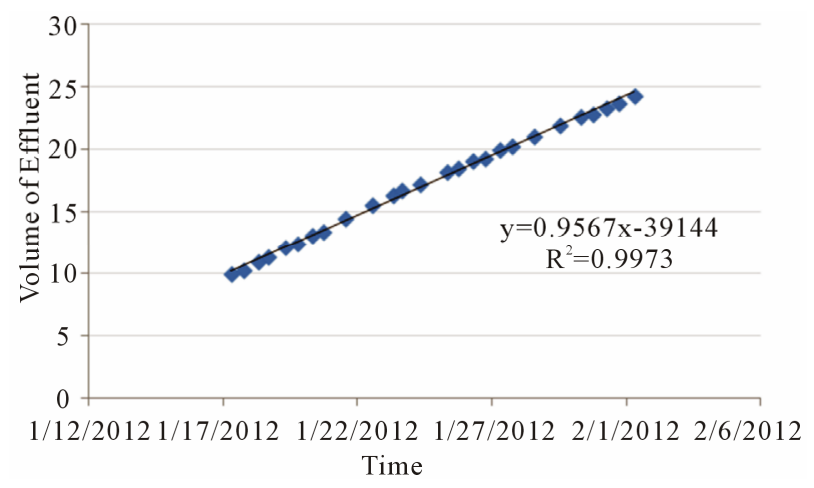

Figure 8. Volume of effluent in the receiving pump for the fractured Kirtland Shale test.

core and the flow rate of brine was observed. This indicates that the permeability of the sample did not change appreciably over the course of the experiment. Examinations of the CT scans of this core over the course of the experiment appear to agree with this conclusion; i.e. there is no noticeable change in the fracture or core as determined by the $\mathrm{CT}$ images.

The medical CT images of these scans were analyzed and converted to bulk density measurements by the use of dual-energy scanning conversion techniques (for details of this technique see Jikich et al. (2010)). The results of this bulk analysis reveal little systematic change in the density of the core during the 23 day experiment. As shown in Figure 9 the overall change in the bulk density of the core varied from 1.4 to $1.5 \mathrm{~g} / \mathrm{cm}^{3}$ (or roughly $7 \%$ ), but not in a systematic fashion that would indicate dissolution or precipitation within the sample. The average density of the Kirtland core as a function of date of scan is shown in Figure 9, and again no systematic change in the density can be noted that would conclusively indicate either precipitation or dissolution of the rock matrix around the fracture.

An entire montage of medical CT scanner XY slices for the Eau Claire sub-core \#1 is shown in Figure 10. The fracture is more apparent within this scan as opposed to the Kirtland fractured sub-core, due to the mechanical fracturing of the sub-core along the length of the sample. Distinct variation in the density of the rock matrix due to the different bedding planes can be noted in Figure 10 by the changes from lighter to darker regions. This matches the variation in the full core seen in the previous CT scans and visual observations of the core. The purple slice in the upper left corner of Figure $\mathbf{1 0}$ is the end of the core brine-saturated- $\mathrm{CO}_{2}$ was injected into. Several features of this fracture can be noted from Figure 10. There are regions where the fracture wall touch; zero aperture zones. This type of contact between surfaces has been shown to dramatically affect the transmissivity of a fracture [8]. Also, there is a secondary fracture perpendicular to the primary fracture roughly $3 / 4$ of the distance from the injection side of the core. Neither of these features hindered flow through the fracture in a meaningful way and a constant injection rate of $0.013 \mathrm{ml} / \mathrm{min}$ was maintained for the entire experiment, with the pore pressure remaining around 1650 psi.

Initial analysis of the CT scans show little change in the fracture structure over the 22 day long experiment. The bulk density of the sample as derived from the CTN of the full XY slices from the medical CT scans showed no significant difference in the average density of the core over the duration of the test. The values plotted in Figure 11 have error bars showing \pm one standard deviation of the bulk density. There was a nominal increase in the density during the last week of the experiment, but the density decreased again by the end of the experiment. The scans during this period were examined to determine if there was some observable phenomenon that occurred 


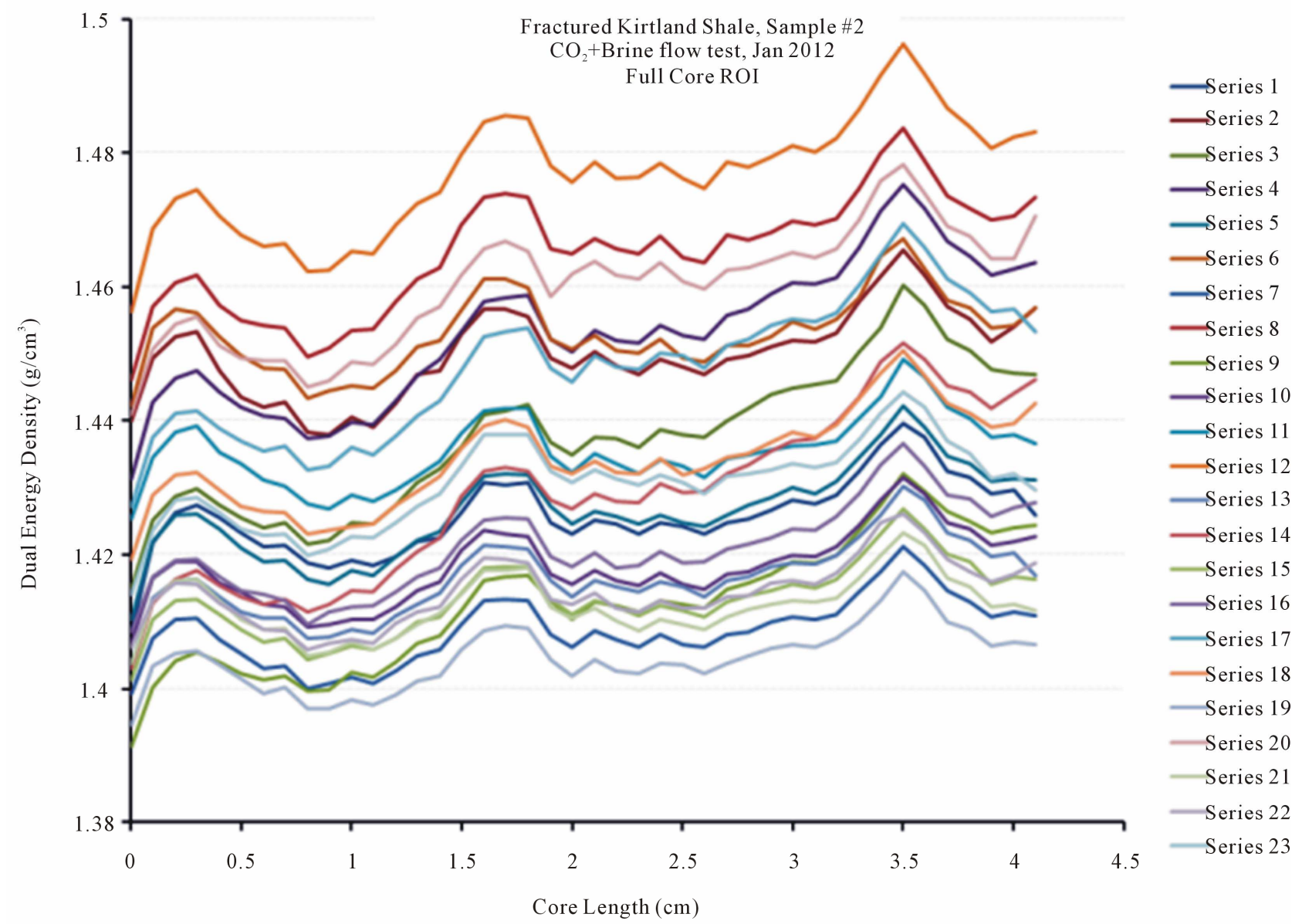

Figure 9. Calculated bulk density of the fractured Kirtland shale core.

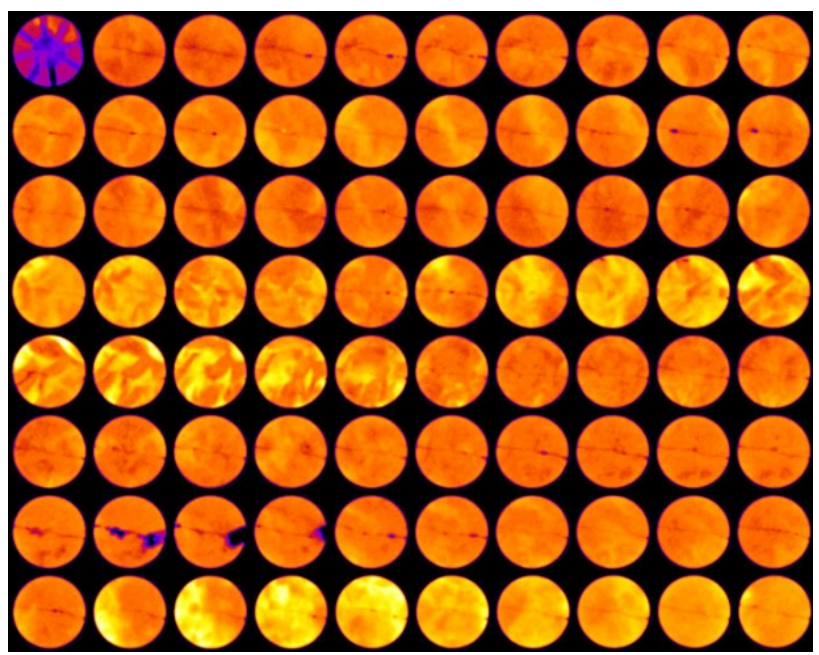

Figure 10. Slices of the medical CT scanner reconstruction of Eau Claire mudstone sub-core \#1.

in this time period. Though no direct causation was found, it is suspected that this change in the bulk density was due to environmental factors within the CT scanner building during this time. A smaller region of interest that encompassed the primary fracture and less of the surrounding rock matrix was used to calculate the bulkdensity of a more focused zone around the fracture. The results, were similar to those shown in Figure $\mathbf{1 1}$ and revealed that the density of this smaller region follows the same trends as the full core bulk density; no conclusive information about changes to the fracture can be derived solely from the CT data.

With multiple sub-cores of the same section of the Eau Claire and the disappointing pressure measurements in the first Eau Claire fractured flow test, an additional test was performed with a similar fractured sample (Figure 3). Initially this flow rate was set to $0.013 \mathrm{ml} / \mathrm{min}$, the fractured core was so permeable the low injection rate had a difficult time in maintaining the pore pressure of $1650 \mathrm{psi}$, so after two days of operation the flow rate was increased to $0.026 \mathrm{ml} / \mathrm{min}$.

The XY slice montage of the medical CT scan slices for the Eau Claire fractured core \#2 is shown in Figure 12. In this representation the primary fracture along the length of the core is shown vertical and in the center of the core. The XZ slice montage is shown in Figure 12 and has a similar bedding plane structure to Eau Claire 


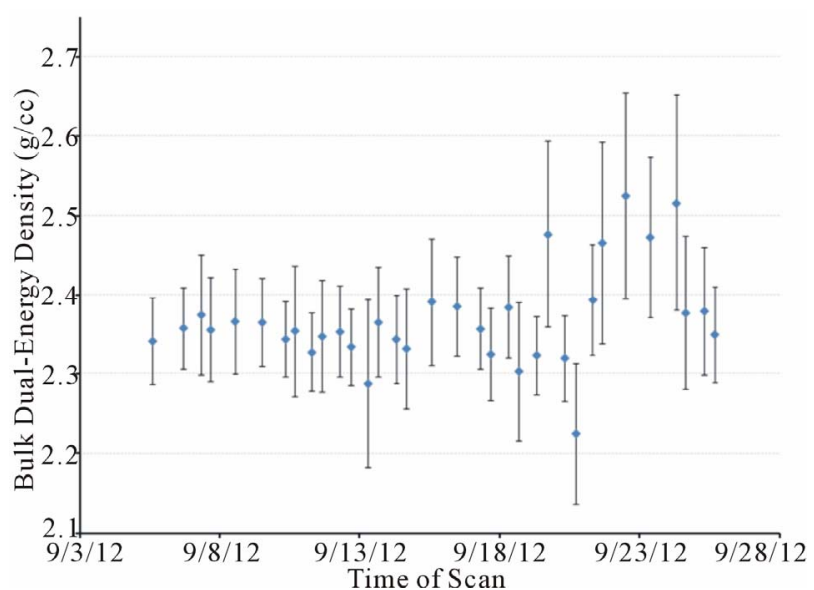

Figure 11. Averaged bulk dual-energy derived density of the entire of the Eau Claire sub-core \#1.

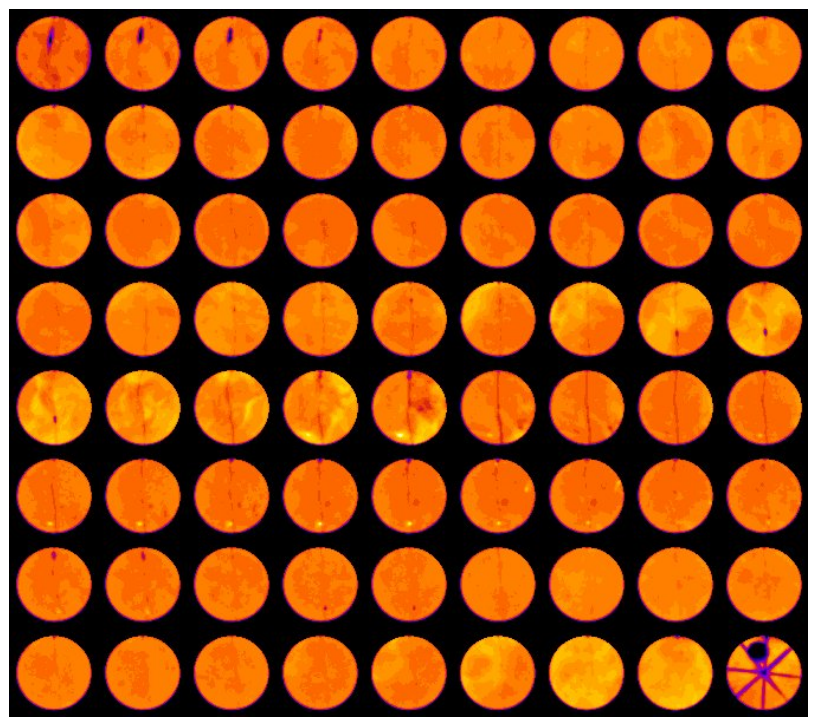

Figure 12. Slices of the medical CT scanner reconstruction of Eau Claire mudstone sub-core \#2.

fractured core \#1.

The medical CT scan derived dual-energy bulk density is shown in Figure 13. Very little variation in the density was observed over the course of this experiment. The outlying data point from the scan on 10/20 was scanned on a weekend day, though the reason for the higher than average density from this scan is unclear. A linear fit to the data shows a very slight increase in the density with a slope of $4\left(10^{-4}\right)$; removing the data from 10/20 does not alter the slope of this fit. Similar to the Eau Claire test \#1, no conclusive changes in the fracture structure can be determined from the medical $\mathrm{CT}$ images alone.

The pressure across the core was measured with a Setra 0 - 250 differential pressure transducer and recorded with a LabView virtual instrument every 30 seconds. This recorded data was averaged over 20 minute intervals and is shown in Figure $\mathbf{1 4}$ over the course of the

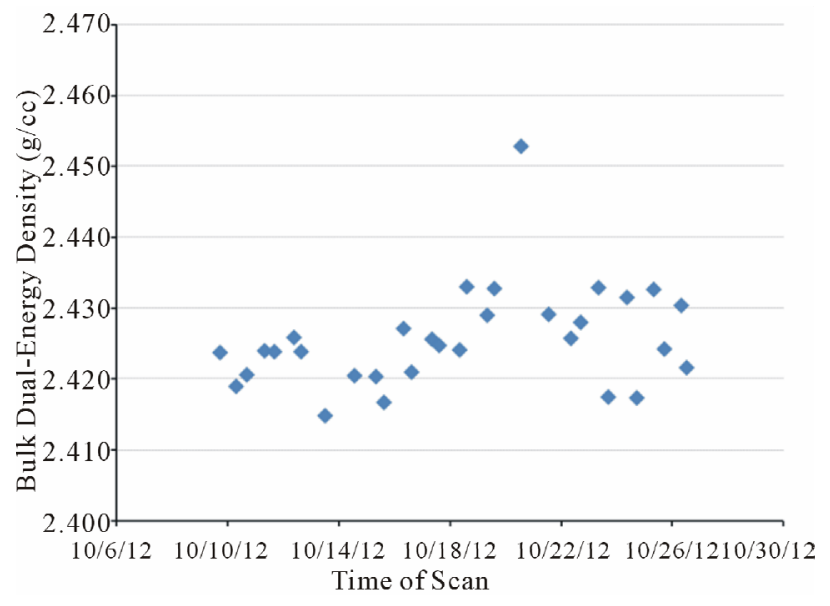

Figure 13. Averaged bulk dual-energy derived density of the entire of the Eau Claire sub-core \#2.

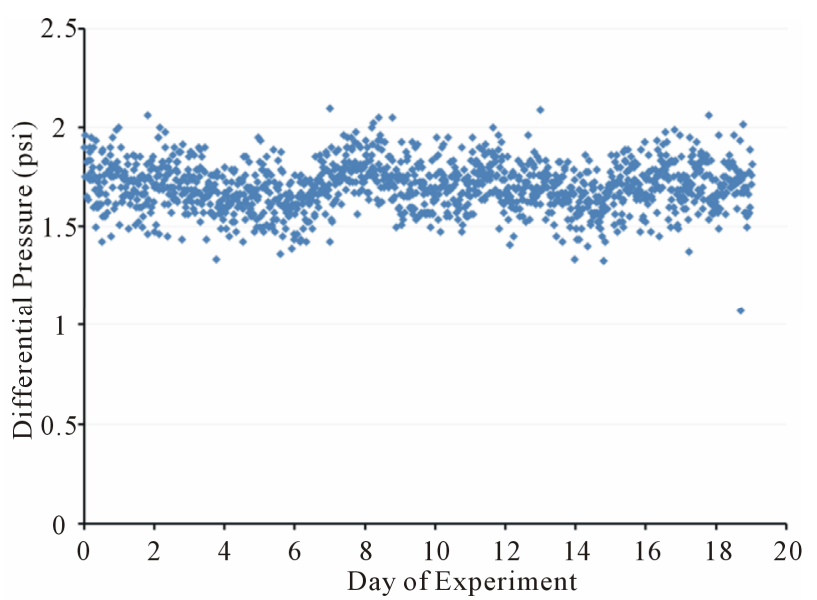

Figure 14. Pressure across Eau Claire sub-core \#2, measured from 0 - 250 psi differential pressure gauge.

experiment. There is a spread in the data between 1.3 and 2.1 (with one outlier at $1.07 \mathrm{psi}$ ), but the general trend is unchanging; a linear fit to the data has a slope of $-10^{-4}$. This lack of change in the pressure indicates that no measurable change in the differential pressure was recorded. The increase in the flow rate from 0.013 to 0.026 on day two of the experiment had no measurable effect on the recorded pressure either.

The final test performed in this series of experiments was a Tuscaloosa claystone. The sample is a sidewall plug that was fractured upon arrival at NETL. This was the only core studied where flow was parallel to the bedding planes. The medical CT scanner XY slice montage of the fractured Tuscaloosa claystone is shown in Figure 15. The core is heterogeneous, with several higher density zones (light regions) and several fractures along the length of the core.

The dual-energy derived density again shows little in the way of observable trends (Figure 16). Several measurements were well below the average density of 2.72 


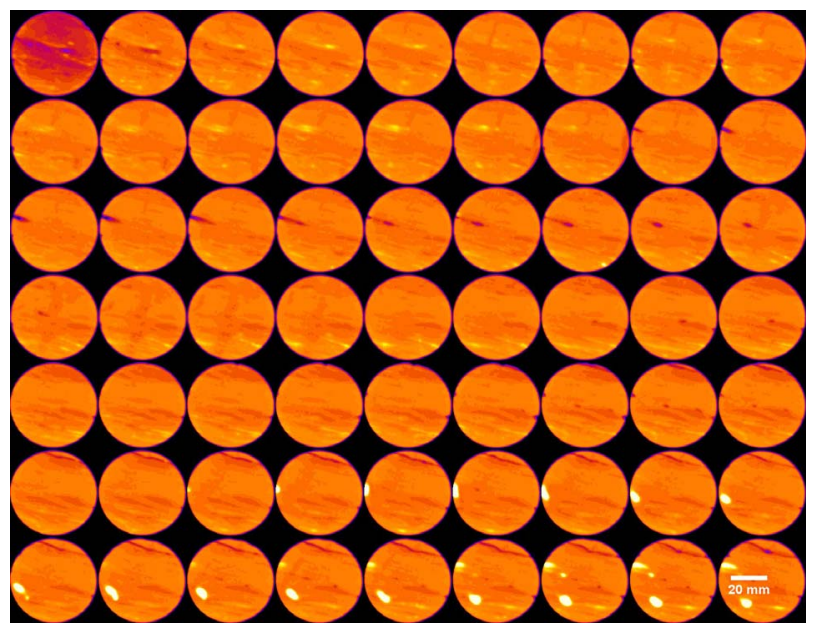

Figure 15. False color medical CT slices of fractured Tuscaloosa claystone sample.

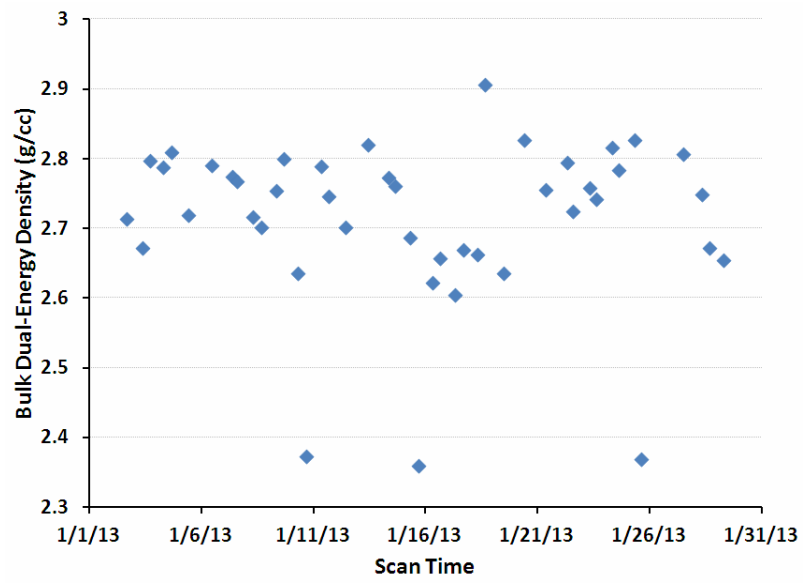

Figure 16. Averaged bulk dual-energy derived density of the Tuscaloosa claystone.

$\mathrm{g} / \mathrm{cc}$. The CT scanner was overdue for maintenance at this point; slight machine errors may have contributed to these values. With the three outliers removed a linear fit has a slope of $10^{-4}$, and thus no changes to the geometry of the core were detectable from the medical CT images alone.

The pressure across the core was measured with the same differential pressure transducer and LabView recording system used for the Eau Claire \#2 fractured sub-core experiment, recorded every 30 seconds. The values averaged every 20 minutes are shown in Figure 17. A noticeable increase in the pressure from $\approx 3.3$ psi to $\approx 4.4 \mathrm{psi}$ was observed. This could be an indication of small amounts of precipitation within the fracture voids that reduced the mechanical and hydraulic aperture of the fracture, an excellent trait for a sealing formation.

\section{Conclusions}

For the three formations studied there was a minimal

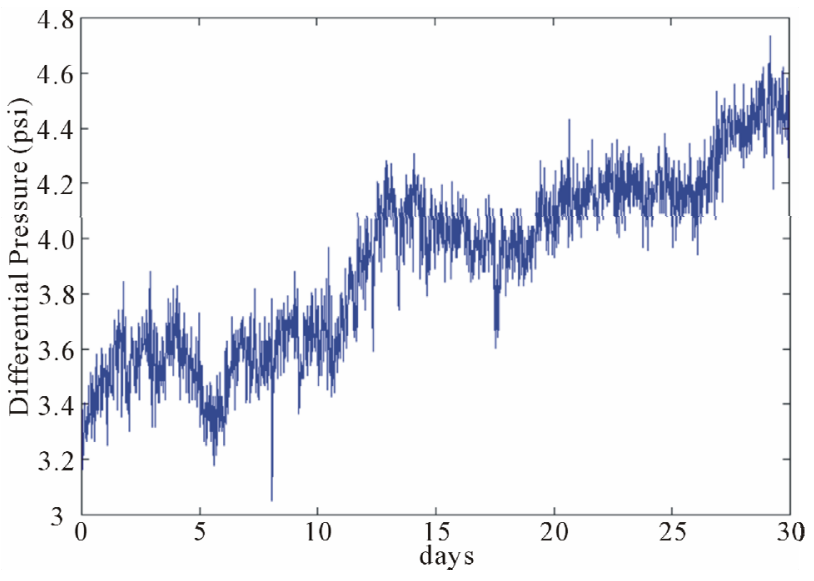

Figure 17. Pressure across Tuscaloosa fractured core, measured from 0 - 250 psi differential pressure gauge.

change in the recordable fracture properties over the course of the extended saturated $\mathrm{CO}_{2}$-brine flow through experiments. This is a good result, indicating that the potential sealing properties of these formations will not degrade when in contact with $\mathrm{CO}_{2}$-saturated brine. Even though these were long tests for laboratory studies, on the geologic scale of interest for CCUS activities they are not "long". As such, longer experiments may yield different results.

In addition, three out of four of these experiments were run at room temperature due to issues with the temperature control mechanism in the medical CT scanner. And increase in the temperature of the cores and fluids may increase the reaction rate and promote more rapid alteration of the fracture structure.

The most dramatic change was the reduction in the hydraulic aperture of the Tuscaloosa fractured sample, as shown by the increase in the differential pressure across the core. This increased resistance to flow could help stem the flow of $\mathrm{CO}_{2} /$ brine from a CCUS reservoir in the Gulf Coast. No other flow properties were observed to change as much.

The lack of change in the fracture hydraulic properties of the fracture indicates that the non-dynamic pressure to flow relationships discussed in the introduction and currently implemented in many discrete fractures flow models is adequate for $\mathrm{CO}_{2}$-brine flow through fractured seals. That is, there appears to be little need for the inclusion of geochemical alterations to the basic fracture flow equations when the reactivity of the surrounding rock matrix material is very low. When other factors may affect the behavior of a fracture (such as changes to the stress field) those factors may need to be included, but geochemical reactions within the seal formations and $\mathrm{CO}_{2}$-brine mixtures studied appear minimal.

\section{Acknowledgements}

Thanks to Bryan Tennant, Karl Jarvis, and Roger Lapeer 
for assistance with all laboratory work. This work was completed as part of National Risk Assessment Partnership (NRAP) project. Support for this project came from the DOE Office of Fossil Energy's Crosscutting Research program. The authors wish to acknowledge Robert Romanosky (NETL Strategic Center for Coal) and Regis Conrad (DOE Office of Fossil Energy) for programmatic guidance, direction, and support.

\section{REFERENCES}

[1] ICCP, "Contribution of Working Group III to the Fourth Assessment Report of the Intergovernmental Panel on Climate Change," B. Metz, O. R. Davidson, P. R. Bosch, R. Dave and L. A. Meyer, Eds., Cambridge University Press, Cambridge, New York, 2007.

[2] NETL, "The United States 2012 Carbon Utilization and Storage Atlas," 4th Edition, p. 130.

http://www.netl.doe.gov

[3] H. A. Loáiciga, " $\mathrm{CO}_{2}$ Capture and Geologic Storage: The Possibilities," Ground Water, 2013, in Press.

[4] R. W. Zimmerman and G. S. Bodvarsson, "Hydraulic Conductivity of Rock Fractures," Transport in Porous Media, Vol. 23, No. 1, 1996, pp. 1-30. http://dx.doi.org/10.1007/BF00145263

[5] B. Berkowitz, "Characterizing Flow and Transport in Fractured Geological Media: A Review," Advances in Water Resources, Vol. 25, No. 8-12, 2002, pp. 861-884.

[6] J. Bear, "Dynamics of Fluids in Porous Media," Courier Dover Publications, New York, 1972.

[7] P. A. Witherspoon, C. H. Amick, J. E. Gale and K. Iwai, "Observations of a Potential Size Effect in Experimental Determination of the Hydraulic Properties of Fractures," Water Resources Research, Vol. 15, No. 5, 1979, pp. 11421146. http://dx.doi.org/10.1029/WR015i005p01142

[8] L. J. Pyrak-Nolte, N. G. W. Cook and D. D. Nolte, "Fluid Percolation through Single Fractures," Geophysical Research Letters, Vol. 15, No. 11, 1988, pp. 1247-1250. http://dx.doi.org/10.1029/GL015i011p01247

[9] J. S. Konzuk and B. H. Kueper, "Evaluation of Cubic Law Based Models Describing Single-Phase Flow through a Rough-Walled Fracture," Water Resources Research, Vol. 40, No. 2, 2004, Article ID: W02402. http://dx.doi.org/10.1029/2003WR002356

[10] D. Crandall, G. Bromhal and Z. T. Karpyn, "Numerical Simulations Examining the Relationship between WallRoughness and Fluid Flow in Fractures," International Journal of Rock Mechanics and Mining Sciences, Vol. 47, No. 5, 2010, pp. 784-796. http://dx.doi.org/10.1016/j.ijrmms.2010.03.015

[11] P. A. Witherspoon, J. S. Y. Wang, K. Iwai and J. E. Gale, "Validity of Cubic Law for Fluid Flow in Deformable Rock Fracture," Water Resources Research, Vol. 16, No. 6, 1980, pp. 1016-1024. http://dx.doi.org/10.1029/WR016i006p01016

[12] L. J. Pyrak-Nolte and J. P. Morris, "Single Fractures under Normal Stress: The Relation between Fracture Spe- cific Stiffness and Fluid Flow," International Journal of Rock Mechanics and Mining Sciences, Vol. 37, 2000, pp. 245-262. http://dx.doi.org/10.1016/S1365-1609(99)00104-5

[13] J. B. Walsh, "The Effect of Pore Pressure and Confining Pressure on Fracture Permeability," International Journal of Rock Mechanics and Mining Sciences, Vol. 18, No. 5, 1981, pp. 429-435. http://dx.doi.org/10.1016/0148-9062(81)90006-1

[14] R. W. Zimmerman, D.-W. Chen and N. G. W. Cook, "The Effect of Contact Area on the Permeability of Fractures," Journal of Hydrology, Vol. 139, 1992, pp. 79-96. http://dx.doi.org/10.1016/0022-1694(92)90196-3

[15] P. Gouze, C. Noiriel, C. Bruderer, D. Loggia and R. Leprovost, "X-Ray Tomography Characterization of Fracture Surfaces during Dissolution," Geophysical Research Letters, Vol. 30, No. 5, 2003, p. 1267. http://dx.doi.org/10.1029/2002GL016755

[16] R. L. Detwiler and H. Rajaram, "Predicting Dissolution Patterns in Variable Aperture Fractures: Evaluation of an Enhanced Depth-Averaged Computational Model," Water Resources Research, Vol. 43, No. 4, 2007, Article ID: W04403. http://dx.doi.org/10.1029/2006WR005147

[17] C. Noiriel, L. Luquot, B. Madé, L. Raimbault, P. Gouze and J. van der Lee, "Changes in Reactive Surface Area during Limestone Dissolution: An Experimental and Modelling Study," Chemical Geology, Vol. 265, No. 1, 2009, pp. 160-170. http://dx.doi.org/10.1016/j.chemgeo.2009.01.032

[18] W. B. Durham, W. L. Bourcier and E. A. Burton, "Direct Observation of Reactive Flow in a Single Fracture," Water Resources Research, Vol. 37, No. 1, 2001, pp. 1-12. http://dx.doi.org/10.1029/2000WR900228

[19] N. J. Huerta, M. A. Hesse, S. L. Bryant, B. R. Strazisar and C. L. Lopano, "Experimental Evidence for Self-Limiting Reactive Flow through a Fractured Cement Core: Implications for the Time-Dependent Wellbore Leakage," Environmental Science \& Technology, Vol. 47, No. 1, 2013, pp. 269-275. http://dx.doi.org/10.1021/es3013003

[20] H. Deng, B. Ellis, C. A. Peters, J. Fitts and D. Crandall, "Modification of Carbonate Fracture Hydrodynamic Properties by $\mathrm{CO}_{2}$-Acidified Brine Flow," Energy Fuels, Vol. 27, No. 8, 2013, pp. 4221-4231. http://dx.doi.org/10.1021/ef302041s

[21] B. R. Ellis, G. S. Bromhal, D. M. McIntyre and C. A. Peters, "Changes in Caprock Integrity Due to Vertical Migration of $\mathrm{CO}_{2}$-Enriched Brine," Energy Procedia, Vol. 4, 2011, pp. 5327-5334. http://dx.doi.org/10.1016/j.egypro.2011.02.514

[22] J. E. Heath, B. J. O. L. McPherson and T. A. Dewers, "Natural Tracers and Multi-Scale Assessment of Caprock Sealing Behavior: A Case Study of the Kirtland Formation, San Juan Basin," Technical Report for the US Department of Energy, DOE Award No. DE-FC26-05NT4 2591, 2011, p. 184.

[23] S. R. Reeves, "The Coal-Seq Project: Key Results from Field, Laboratory and Modeling Studies," Proceedings of the 7th International Conference on Greenhouse Gas Control Technologies (GHGT-7), Vancouver, 5-9 September 
2004, pp. 1399-1406.

[24] D. Haerer and B. McPherson, "Evaluating the Impacts and Capabilities of Long Term Subsurface Storage in the Context of Carbon Sequestration in the San Juan Basin, NM and CO," Energy Procedia, Vol. 1, No. 1, 2009, pp. 2991-2998.

http://dx.doi.org/10.1016/j.egypro.2009.02.076

[25] T. H. Wilson, A. Wells, D. Peters, A. Mioduchowski, G. Martinez, G. Koperna, B. N. Akwari and J. Heath, "Fracture and 3D Seismic Interpretations of the Fruitland Formation and Cover Strata: Implications for $\mathrm{CO}_{2}$ Retention and Tracer Movement, San Juan Basin Pilot Test," International Journal of Coal Geolog, Vol. 99, 2012, pp. 3553. http://dx.doi.org/10.1016/j.coal.2012.02.007

[26] J. McCord, M. Reiter and F. Phillips, "Heat-flow Data Suggest Large Ground-Water Fluxes through Fruitland Coals of the Northern San Juan Basin, Colorado-New Mexico," Geology, Vol. 20, No. 5, 1992, pp. 419-422. http://dx.doi.org/10.1130/0091-7613(1992)020<0419:HF DSLG $>2.3 . \mathrm{CO} ; 2$

[27] C. Sullivan, T. Gilmore, J. Horner, M. Kelley, D. Appriou and J. Hoffman, "Update on the FutureGen2.0 Characterization Well Activities in Morgan County, Illinois," presented at the $11^{\text {th }}$ Annual Conference on Carbon Capture, Utilization, \& Sequestration, Pittsburgh, 30 April-3 May 2012.

[28] S. A. Carroll, W. W. McNab, Z. Dai and S. C. Torres, "Reactivity of Mount Simon Sandstone and the Eau Claire Shale under $\mathrm{CO}_{2}$ Storage Conditions," Environmental Science and Technology, Vol. 47, No. 1, 2012, pp. 252261. http://dx.doi.org/10.1021/es301269k

[29] F. Liu, P. Lu, C. Griffith, S. W. Hedges, Y. Soong, H. Hellevang and C. Zhu, " $\mathrm{CO}_{2}$-Brine-Caprock Interaction: Reactivity Experiments on Eau Claire Shale and a Review of Relevant Literature," International Journal of Greenhouse Gas Control, Vol. 7, 2012, pp. 153-167. http://dx.doi.org/10.1016/j.ijggc.2012.01.012

[30] C. A. Griffith, D. A. Dzombak and G. V. Lowry, "Physical and Chemical Characteristics of Potential Seal Strata in Regions Considered for Demonstrating Geological Saline $\mathrm{CO}_{2}$ Sequestration," Environmental Earth Sciences, Vol. 64, No. 4, 2011, pp. 925-948. http://dx.doi.org/10.1007/s12665-011-0911-5

[31] B. Brown, K. J. Nereth, R. Rhudy and R. Esposito, "Southeast Regional Carbon Partnership (SECARB)," The Mississippi Test Site Fact Sheet, 2013. www.secarbon.org

[32] J. Lu, Y. K. Kharaka, J. J. Thordsen, J. Horita, A. Karamalidis, C. Griffith, J. A. Hakala, G. Ambats, D. R. Cole, T. J. Phelps, M. A. Manning, P. J. Cook and S. D. Hovoka, " $\mathrm{CO}_{2}$-Rock Brine Interactions in Lower Tuscaloosa Formation at Cranfield $\mathrm{CO}_{2}$ Sequestration Site, Mississippi, USA," Chemical Geology, Vol. 291, 2012, pp. 269277. http://dx.doi.org/10.1016/j.chemgeo.2011.10.020

[33] S. L. Wellington and H. J. Vinegar, "Tomographic Imaging of Three-Phase Flow Experiments," Review of Scientific Instruments, Vol. 58, No. 1, 1987, pp. 96-107. http://dx.doi.org/10.1063/1.1139522

[34] S. A. Jikich, D. McIntyre, G. S. Bromhal and D. Crandall, "Mechanical Properties, Flow Properties, and Heterogeneous $\mathrm{CO}_{2}$ Sorption in Confined Powder River Basin Coal Cores," 44th US Rock Mechanics Symposium and 5th US-Canada Rock Mechanics Symposium, 2010.

[35] C. S. Santarosa, D. Crandall, I. V. Haljasmaa, T.-B. Hur, J. J. Fazio, R. P. Warzinski, R. Heemann, J. M. M. Ketzer and V. N. Romanov, "CO $\mathrm{CO}_{2}$ Sequestration Potential of Charqueadas Coal Field in Brazil," International Journal of Coal Geology, Vol. 106, 2013, pp. 25-34. http://dx.doi.org/10.1016/j.coal.2013.01.005 